\title{
Curcumin synergistically enhances the radiosensitivity of human oral squamous cell carcinoma via suppression of radiation-induced NF- $\kappa B$ activity
}

\author{
I-TSANG CHIANG $^{1 *}$, YU-CHANG LIU $^{1,2^{*}}$, FEI-TING HSU ${ }^{1 *}$, YI-CHUN CHIEN $^{1,3}$, \\ CHIH-HAO K. KAO ${ }^{4}$, WUU-JYH LIN ${ }^{5}$, JING-GUNG CHUNG ${ }^{6}$ and JENG-JONG HWANG ${ }^{1}$
}

\author{
${ }^{1}$ Department of Biomedical Imaging and Radiological Sciences, National Yang-Ming University, Taipei; \\ ${ }^{2}$ Department of Radiation Oncology, National Yang-Ming University Hospital, Yilan; ${ }^{3}$ Department of Medical Imaging \\ and Radiological Sciences, I-Shou University, Kaohsiung; ${ }^{4}$ Department of Radiopharmaceutical Production, \\ Hualien Tzu Chi Hospital, Hualien; ${ }^{5}$ Division of Radioisotope, Institute of Nuclear Energy Research, Taoyuan; \\ ${ }^{6}$ Department of Biological Science and Technology, China Medical University, Taichung, Taiwan, R.O.C.
}

Received September 16, 2013; Accepted November 11, 2013

DOI: 10.3892/or.2014.3009

\begin{abstract}
The anticancer effect of curcumin has been widely reported. However, whether curcumin can enhance the radiosensitivity of human oral squamous cell carcinoma (OSCC) remains to be elucidated. The aim of the present study was to evaluate the efficacy of curcumin combined with radiation against OSCC. SAS cells were transfected with the luciferase gene $(l u c)$ and named SAS/luc. NF-кB/DNA binding activity, the surviving fraction and NF- $\mathrm{KB}$-regulated effector protein expression were determined by electrophoretic mobility shift assay, clonogenic survival assay and western blotting, respec-
\end{abstract}

Correspondence to: Professor Jeng-Jong Hwang, Department of Biomedical Imaging and Radiological Sciences, National Yang-Ming University, No. 155, Sec. 2, Li-Nong Street, Bei-tou, Taipei 112, Taiwan, R.O.C.

E-mail: jjhwang@ym.edu.tw

${ }^{*}$ Contributed equally

Abbreviations: BCL-2, B-cell lymphoma 2 protein; BLI, bioluminescence imaging; CCRT, combined chemotherapy and radiotherapy; C-FLIP, cellular FLICE-like inhibitory protein; COX-2, cyclooxygenase-2; DMEM, Dulbecco's modified essential medium; ECL, enhanced chemiluminescence; EGFR, epidermal growth factor receptor; ELISA, enzyme-linked immunosorbent assay; EMSA, electrophoretic mobility shift assay; HIF- $\alpha$, hypoxia-inducible factor- $\alpha$; luc, luciferase gene; MTT, 3-(4,5-dimethylthiazol-2-yl)-2,5diphenyltetrazolium bromide; MMP-9, matrix metalloproteinase-9; $\mathrm{NF}-\kappa \mathrm{B}$, nuclear factor- $\kappa \mathrm{B}$; OSCC, oral squamous cell carcinoma; p-IкB $\alpha \mathrm{M}, \mathrm{NF}-\kappa \mathrm{B}$ super-repressor; SDS-PAGE, sodium dodecyl sulfate polyacrylamide gel electrophoresis; SF, surviving fraction; SSD, source-to-skin distance; TNF- $\alpha$, tumor necrosis factor- $\alpha$; TPA, 12-O-tetradecanoylphorbol-13-acetate; VEGF, vascular endothelial growth factor; XIAP, $\mathrm{x}$-linked inhibitor of apoptosis protein

Key words: curcumin, radiotherapy, nuclear factor- $\mathrm{\kappa}$ tively. The therapeutic efficacy was evaluated in SAS/luc tumor-bearing mice by caliper measurement and bioluminescence imaging. Curcumin enhanced SAS/luc radiosensitivity through the inhibition of radiation-induced NF- $\kappa \mathrm{B}$ activity and expression of effector proteins both in vitro and in vivo. With 4 Gy or greater radiation doses, synergistic effects of curcumin were observed. The combination group (curcumin plus radiation) had significantly better tumor control compared with that of curcumin or radiation alone. No significant body weight change of mice was found throughout the entire study. In conclusion, curcumin is a radiosensitizer against OSCC with negligible toxicity.

\section{Introduction}

Oral squamous cell carcinoma (OSCC) is the most common head and neck cancer in Taiwan. Radiotherapy plays a major role in the postoperative or definitive treatment for patients with locoregionally advanced disease. Unfortunately, more than half of high-risk patients develop locoregional recurrence and/or distant metastasis despite aggressive treatment (1). Radioresistance has been described in the literature to be related to several signaling pathways, such as cyclooxygenase-2 (COX-2), matrix metalloproteinase-9 (MMP-9), tumor necrosis factor- $\alpha$ (TNF- $\alpha$ ) and hypoxia-inducible factor- $\alpha$ (HIF- $\alpha)(2-4)$. Nuclear factor- $\kappa B$ (NF- $\kappa B$ ) is the key molecule for relaying signals from these pathways to express downstream effectors, which are responsible for radioresistance (2).

Irradiation is able to activate $\mathrm{NF}-\kappa \mathrm{B}$ and subsequent transcription of effector proteins governing cell proliferation (such as cyclin D1), angiogenesis [such as vascular endothelial growth factor (VEGF)], invasion (such as MMP-9), and antiapoptosis [such as B-cell lymphoma 2 protein (BCL-2), $\mathrm{x}$-linked inhibitor of apoptosis protein (XIAP) and cellular FLICE-like inhibitory protein (C-FLIP)], resulting in radioresistance and poorer treatment outcome $(5,6)$. These NF- $\mathrm{kB}$-regulated effectors (i.e. cyclin D1, VEGF, MMP-9, BCL-2 and XIAP) have 
been suggested to be biomarkers indicating cancer treatment resistance in OSCC (7-10).

Inhibition of the NF- $\kappa \mathrm{B}$ signaling cascade increases cancer cell sensitivity to radiotherapy and chemotherapy $(11,12)$. In addition, tumor infiltrating inflammatory and stromal cells in the microenvironment promote prosurvival and oncogenic signals through activation of $\mathrm{NF}-\kappa \mathrm{B}$, which appears to be an appropriate target for cancer therapy from the aspect of reversing therapeutic resistance (6).

In comparison with radiotherapy alone, combined chemotherapy and radiotherapy (CCRT) simultaneously could enhance locoregional control and disease-free survival in patients with high-risk head and neck cancer. However, acute severe toxicity occurs more frequently in patients receiving CCRT and may affect treatment compliance and even result in treatment-related death (13). An ideal radiosensitizer should enhance the radiosensitivity of cancer cells to achieve better tumor control without increasing normal tissue toxicity. Curcumin, commonly known as the spice turmeric, is a polyphenol derived from the plant Curcuma longa, and has been shown to have anticancer, antioxidant and anti-inflammatory effects (14). When embedded with liposome and administered intravenously, curcumin is able to reduce radiation-induced lung damage (15). Treating OSCC with curcumin was found to result in growth inhibition through suppression of $\mathrm{NF}-\kappa \mathrm{B}$ (16). Radiation combined with curcumin was found to have an additive effect on head and neck squamous cell carcinoma possibly through inhibition of epidermal growth factor receptor (EGFR) phosphorylation and COX-2 expression (17). Nevertheless, whether curcumin can sensitize OSCC to radiation via suppression of $\mathrm{NF}-\kappa \mathrm{B}$ activation has not yet been elucidated. In the present study, we used molecular imaging to evaluate the therapeutic efficacy of curcumin combined with radiation on luciferase reporter gene $(l u c)$-carrying OSCC cell line (SAS/luc) tumor-bearing mice. The effect of curcumin on radiation-induced $\mathrm{NF}-\kappa \mathrm{B}$ activity and $\mathrm{NF}-\kappa \mathrm{B}$ regulated products in $\mathrm{SAS} / l u c$ cells was also investigated. In order to verify the role of $\mathrm{NF}-\kappa \mathrm{B}$ inhibition, SAS cells were transfected with $\mathrm{NF}-\kappa \mathrm{B}$ super-repressor $(\mathrm{p}-\mathrm{I} \kappa \mathrm{B} \alpha \mathrm{M})$. The combined effects of $\mathrm{p}-\mathrm{I} \kappa \mathrm{B} \alpha \mathrm{M}$ transfection and radiation on SAS cells were studied.

\section{Materials and methods}

Experimental design. The in vitro and in vivo studies were divided into two parts. The first part was to investigate whether curcumin has a radiosensitizing effect and the experiments were subdivided into four groups: the control group (control or vehicle), curcumin-treated group (curcumin alone), radiationtreated group (radiation alone) and combined treatment group (combination). The other part was to verify the effect of the $\mathrm{I} \kappa \mathrm{B} \alpha \mathrm{M}$ vector, which represses constitutive or radiationinduced $\mathrm{NF}-\kappa \mathrm{B}$ activity, to radiosensitize the OSCC cell line. This experiment was also subdivided into four groups: empty vector-transfected group (empty vector), $\mathrm{p}$-I $\kappa \mathrm{B} \alpha \mathrm{M}$-transfected group ( $\mathrm{\kappa} \kappa \mathrm{B} \alpha \mathrm{M}$ vector), radiation-treated group (radiation alone) and $\mathrm{p}-\mathrm{I} \kappa \mathrm{B} \alpha \mathrm{M}$-transfection plus radiation group (combination). The Experimental Animal Care and Use Committee of the National Yang-Ming University Office of Research and Development approved the experiment.
Plasmid transfection and stable clone selection. Stable clones of SAS/luc cells were established as described in our previous study (18). In brief, SAS cells were transfected with the pC1-luc vector using jetPEI ${ }^{\mathrm{TM}}$ (Polyplus Transfection, Sélestat, France). Cells $\left(2 \times 10^{5}\right)$ were seeded in a $100-\mathrm{mm}$ diameter dish containing $3 \mathrm{ml}$ Dulbecco's modified essential medium (DMEM; Gibco-Life Technologies, Grand Island, NY, USA) $24 \mathrm{~h}$ before transfection. pC1-luc $(5 \mu \mathrm{l})$ and $10 \mu \mathrm{l}$ of jetPEI ${ }^{\mathrm{TM}}$ solution were diluted in $500 \mu \mathrm{l}$ of $150 \mathrm{mM} \mathrm{NaCl}$, respectively, then mixed together and incubated for $30 \mathrm{~min}$ at $37^{\circ} \mathrm{C}$. The jetPEI/plasmid vector mixture was added to SAS cells and incubated at $37^{\circ} \mathrm{C}$ for another $24 \mathrm{~h}$. Cells were then trypsinized and cultured in 100-mm dishes with DMEM containing $1 \mathrm{mg} / \mathrm{ml} \mathrm{G} 418$ (Merck, Darmstadt, Germany) supplemented with $10 \%$ fetal bovine serum (FBS; Biological Industries, Beit Haemek, Israel) for 2 weeks. The surviving clones were isolated and transferred to 96-well plates for growth. The Luc protein expression in each clone was assayed using BLI. The recombinant bioluminescent cell clone was named SAS/luc.

The I $\kappa \mathrm{B} \alpha$ mutant vector ( $\mathrm{p}-\mathrm{I} \kappa \mathrm{B} \alpha \mathrm{M}$; Clontech, Mountain View, CA, USA) was used to transfect SAS cells using the same protocol as in our previous study (19). The inhibitory effect of $\mathrm{p}-\mathrm{I} \kappa \mathrm{B} \alpha \mathrm{M}$ super repressor on $\mathrm{NF}-\kappa \mathrm{B}$ activation was confirmed with electrophoretic mobility shift assay (EMSA). $\mathrm{p}-\mathrm{I} \kappa \mathrm{B} \alpha \mathrm{M}$-transfected SAS cells were used as a negative control of $\mathrm{NF}-\kappa \mathrm{B}$ activation.

Cell culture. SAS/luc cells were cultured in DMEM supplemented with $10 \% \mathrm{FBS}$ and $100 \mathrm{U} / \mathrm{ml}$ penicillin plus $100 \mu \mathrm{g} / \mathrm{ml}$ streptomycin (Gibco-Life Technologies) at $37^{\circ} \mathrm{C}$ in a humidified atmosphere of $5 \% \mathrm{CO}_{2}$. G418 $(500 \mu \mathrm{g} / \mathrm{ml})$ was added to the medium to maintain the stable expression of the $l u c$ gene.

Cytotoxicity of curcumin. SAS/luc cells were seeded in 96-well plates (3,000 cells/well), incubated for $24 \mathrm{~h}$, and then treated with different concentrations $(0-50 \mu \mathrm{M})$ of curcumin (Sigma-Aldrich, St. Louis, MO, USA) for another 24 or $48 \mathrm{~h}$. Cells were then washed with fresh medium. Subsequently, $100 \mu \mathrm{l}$ of $5 \mathrm{mg} / \mathrm{ml} \mathrm{3-(4,5-dimethylthiazol-2-yl)-2,5-diphenyl}$ tetrazolium bromide (MTT) solution was added into each well and incubated for $4 \mathrm{~h}$ at $37^{\circ} \mathrm{C}$. After removing the MTT solution, cells were exposed to $100 \mu 1$ of dimethyl sulfoxide for $5 \mathrm{~min}$, and plates were scanned with an enzyme-linked immunosorbent assay (ELISA) reader (PowerWave X340; BioTek, Winooski, VT, USA) using a test wavelength of $570 \mathrm{~nm}$ and a reference wavelength of $630 \mathrm{~nm}$.

Clonogenic survival assay. SAS/luc cells $\left(1 \times 10^{6}\right)$ were seeded in 100-mm dishes ( 2 dishes per group), incubated for $24 \mathrm{~h}$, and then treated with or without $30 \mu \mathrm{M}$ curcumin (i.e. half maximal inhibitory concentration, $\mathrm{IC}_{50}$ ). Cells were irradiated immediately with various doses (2-12 Gy) using an X-ray irradiator (RS 2000; Rad Source Technologies, Suwanee, GA, USA) at a dose rate of $1.03 \mathrm{~Gy} / \mathrm{min}, 80 \mathrm{~cm}$ source-to-skin distance (SSD) and field size of $30 \times 30 \mathrm{~cm}^{2}$. After irradiation, cells were incubated for $24 \mathrm{~h}$. After that, cells were trypsinized, washed and resuspended in fresh medium, and then seeded in 100-mm diameter dishes. Twelve days later, the cell colonies were fixed with methanol:acetic acid (3:1) solution and stained with $2 \%$ crystal violet. The cell colony was deemed surviving when 
there were $>50$ cells. The surviving fraction $(\mathrm{SF})$ was defined as the ratio of surviving colonies to the number of plated cells with correction for plating efficiency. The radiosensitization effect of curcumin on SAS/luc cells was evaluated according to the formulas (as listed below) suggested by Valeriote and Lin (20) and Carpentier et al (21).

Synergism, $\mathrm{SF}_{\mathrm{R}+\mathrm{C}}<\mathrm{SF}_{\mathrm{R}} \times \mathrm{SF}_{\mathrm{C}}$;

Additivity, $\mathrm{SF}_{\mathrm{R}+\mathrm{C}}=\mathrm{SF}_{\mathrm{R}} \times \mathrm{SF}_{\mathrm{C}}$;

Sub-additivity, $\mathrm{SF}_{\mathrm{R}+\mathrm{C}}>\mathrm{SF}_{\mathrm{R}} \times \mathrm{SF}_{\mathrm{C}}$, with $\mathrm{SF}_{\mathrm{R}+\mathrm{C}}<\mathrm{SF}_{\mathrm{R}}$ and

$\mathrm{SF}_{\mathrm{R}+\mathrm{C}}<\mathrm{SF}_{\mathrm{C}}$;

Antagonism, $\mathrm{SF}_{\mathrm{R}+\mathrm{C}}>\mathrm{SF}_{\mathrm{R}}$ and/or $\mathrm{SF}_{\mathrm{R}+\mathrm{C}}>\mathrm{SF}_{\mathrm{C}}$,

where $\mathrm{SF}_{\mathrm{R}}$ is the surviving fraction of SAS/luc cells treated by radiation alone; $\mathrm{SF}_{\mathrm{C}}$ is the surviving fraction of $\mathrm{SAS} /$ luc cells treated with $\mathrm{IC}_{50}$ curcumin alone $\left(\mathrm{SF}_{\mathrm{C}}=0.5\right) ; \mathrm{SF}_{\mathrm{R}+\mathrm{C}}$ is the surviving fraction of $\mathrm{SAS} / \mathrm{luc}$ cells treated by radiation plus $\mathrm{IC}_{50}$ curcumin.

The surviving fraction of SAS/luc cells transfected with the empty or $\mathrm{p}-\mathrm{I} \kappa \mathrm{B} \alpha \mathrm{M}$ vector was obtained using the same procedure as mentioned above.

Electrophoretic mobility shift assay (EMSA). After treatment with 6 Gy irradiation, $30 \mu \mathrm{M}$ curcumin for $24 \mathrm{~h}$, or a combination of both, a nuclear extraction kit (Chemicon, EMD Millipore, Billerica, MA, USA) was used to isolate the nuclear fractions of SAS/luc cells. The protocol for $\mathrm{NF}-\kappa \mathrm{B} / \mathrm{DNA}$ binding activity evaluation followed the instructions provided with the kit (LightShift Chemiluminescent EMSA kit; Thermo Scientific Pierce Protein Biology Products, Rockford, IL, USA). The following DNA sequences were synthesized for EMSA analysis: sense, AGTTGAGGGGACTTTCCCAGGC and antisense, GCCTGGGAAAGTCCCCTCAACT. Nuclear extracts were incubated with the biotin-labeled DNA probe for $20 \mathrm{~min}$ at room temperature. The DNA-protein complex was separated from the free oligonucleotides on a $5 \%$ polyacrylamide gel, transferred to a nylon membrane and cross-linked by UV light. The membrane was incubated with streptavidinhorseradish peroxidase and detected by enhanced chemiluminescence (ECL; Thermo Scientific Pierce Protein Biology Products).

DNA fragmentation. SAS/luc cells $\left(1 \times 10^{6}\right)$ were grown in 6-well plates and treated with $6 \mathrm{~Gy}$ irradiation, $30 \mu \mathrm{M}$ curcumin for $24 \mathrm{~h}$ or a combination of both. After treatment, a genomic DNA purification kit (Axygen, Tewksbury, MA, USA) was used to extract fragmented DNA following the protocol provided by the manufacturer. DNA laddering was analyzed with $1.5 \%$ agarose gel electrophoresis.

Western blotting. SAS/luc cells $\left(2 \times 10^{6}\right)$ were seeded into $100-\mathrm{mm}$ diameter dishes and treated with $30 \mu \mathrm{M}$ curcumin, 6 Gy irradiation or a combination of both. The cells were then lysed with $100 \mu \mathrm{l}$ lysis buffer $(50 \mathrm{mM}$ Tris- $\mathrm{HCl}, \mathrm{pH} 8.0$, $120 \mathrm{mM} \mathrm{NaCl}, 0.5 \%$ NP-40, $1 \mathrm{mM}$ phenylmethanesulfonyl fluoride). Total proteins (40 $\mu \mathrm{g})$ were separated by $10 \%$ sodium dodecyl sulfate polyacrylamide gel electrophoresis (SDS-PAGE) and transferred to a polyvinylidene fluoride membrane (EMD Millipore). The membranes were blocked with $5 \%$ non-fat milk for $1 \mathrm{~h}$, and probed with the appropriate primary antibody (VEGF, MMP-9, BCL-2, XIAP, C-FLIP, cleaved-caspase-3, caspase-8, cytochrome $c$ and $\beta$-actin; EMD Millipore) overnight at $4^{\circ} \mathrm{C}$. The membranes were then washed in Tris-Tween buffer saline and incubated with horseradish peroxidase-conjugated secondary antibodies (Jackson ImmunoResearch Laboratories, West Grove, PA, USA) at room temperature for $1 \mathrm{~h}$. Final quantification was achieved by using an ECL detection system (EMD Millipore). A cytosol/nuclear extraction kit (Chemicon International, Temecula, CA, USA) was used to isolate cytosolic cytochrome $c$ following the instructions provided with the kit (22).

Tumor-bearing animal model. Six-week-old male NOD/SCID mice were purchased from the National Laboratory Animal Center, Taipei, Taiwan. SAS/luc cells $\left(1 \times 10^{6}\right)$ in $0.2 \mathrm{ml}$ serumfree medium were inoculated subcutaneously into the right legs of NOD/SCID mice. When the tumor volume reached $70 \mathrm{~mm}^{3}$, mice were randomized into four groups ( $\mathrm{n}=5$ for each group) according to the treatment modality: i) control group (phosphate-buffered solution with $1 \%$ dimethyl sulfoxide by gavage daily); ii) curcumin alone group $(70 \mathrm{mg} / \mathrm{kg} / \mathrm{day}$ by gavage from day 1 for 3 weeks); iii) radiation alone group (single dose 6 Gy on day 1); and iv) combination group (70 mg/ $\mathrm{kg} /$ day by gavage from day 1 for 3 weeks plus 6 Gy irradiation on day 1). The treatment protocol for mice is depicted in Fig. 4. Tumor volume was measured by caliper weekly and calculated by the following formula (23): Volume $=1 / 2 \times(4 / 3) \pi \times$ length $/ 2$ $\mathrm{x}$ width $/ 2 \mathrm{x}$ thickness $=0.523 \mathrm{x}$ (length $\mathrm{x}$ width $\mathrm{x}$ thickness).

The body weight of mice was monitored after treatment together with tumor volume tracking. Mice were sacrificed on day 21 for pathologic examination of the liver. All animal experiments complied with institutional animal care guidelines.

In vivo bioluminescent imaging (BLI). SAS/luc tumor-bearing mice received $150 \mathrm{mg} / \mathrm{kg}$ D-luciferin injection intraperitoneally. Before imaging, mice were anesthetized using 1-3\% isoflurane for $15 \mathrm{~min}$ and continuously exposed to $1-2 \%$ isoflurane to maintain a sedative state during imaging. The photons emitted from the tumors were detected in vivo by IVIS 50 Imaging system (Xenogen Corp., Alameda, CA, USA). Image acquisition time was $10 \mathrm{sec}$. Regions of interest (ROIs) were drawn around the tumor and quantified as photons/second ( $\mathrm{p} /$ sec) using Living Image software (Xenogen). In vivo BLI was performed once a week for three weeks, and the serial bioluminescent signals were quantified and displayed over time.

Ex vivo EMSA. Mice were sacrificed on day 21 of the treatment period, and tumors were removed for nuclear protein extraction by using a nuclear extraction kit. The NF- $\kappa \mathrm{B} / \mathrm{DNA}$ binding activity was evaluated using LightShift Chemiluminescent EMSA kit.

Ex vivo western blotting. Mice were sacrificed on day 21 of the treatment period and tumors were removed for protein extraction using the T-PER kit (Thermo Scientific Pierce Protein Biology Products). Equal amounts of protein (40 $\mu \mathrm{g})$ were loaded on SDS-PAGE for electrophoresis and then transferred to nitrocellulose membranes. The membranes were incubated with primary antibodies specific for VEGF, MMP-9, BCL-2, XIAP, C-FLIP, cleaved caspase-3, caspase-8, cytochrome $c$ 


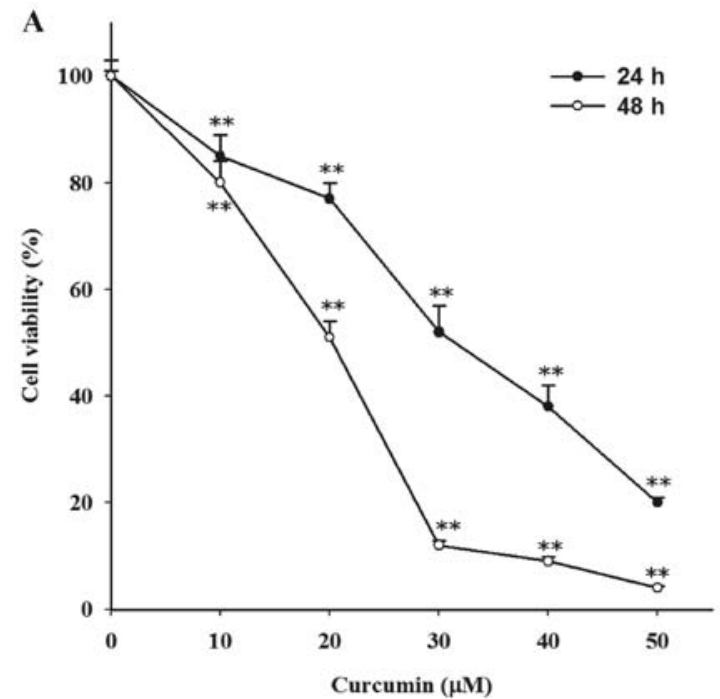

B

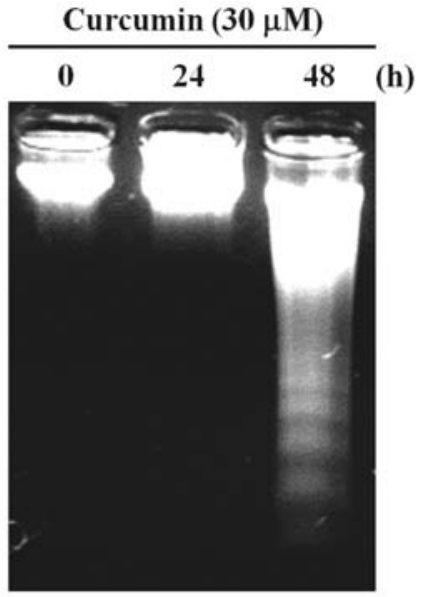

C

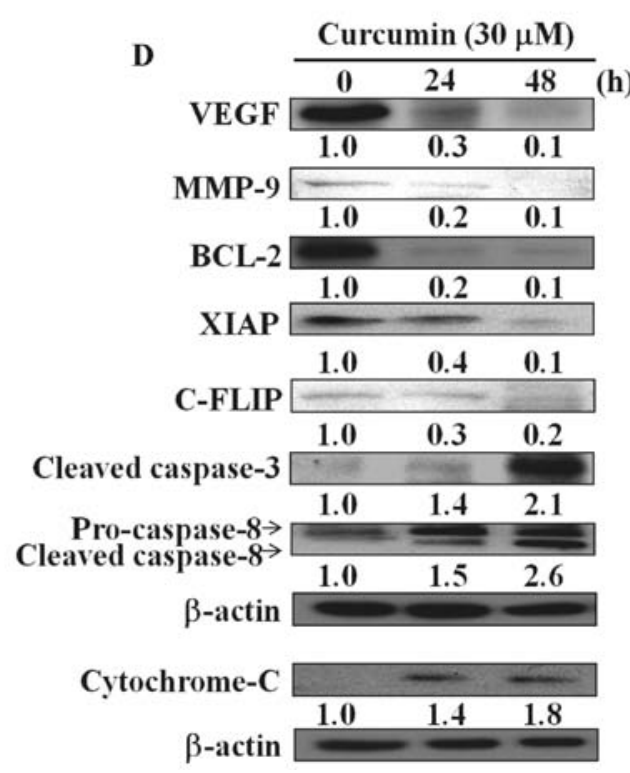

Figure 1. Curcumin inhibits tumor progression of SAS/luc cells in a time-dependent manner. (A) The SAS/luc cells were treated with $0-50 \mu \mathrm{M}$ curcumin for 24 or $48 \mathrm{~h}$. The cell viability was evaluated using an MTT assay. (B) Curcumin induced DNA fragmentation. (C) The result of EMSA indicated that the NF- $\mathrm{kB} /$ DNA binding activity was suppressed by curcumin. (D) Western blotting revealed changes in the level of apoptotic-related and NF- $\kappa B$-regulated proteins after curcumin treatment. $\beta$-actin was used as an internal control. Representative data from three independent experiments are shown. ${ }^{* * *} \mathrm{P}<0.01$.

and $\beta$-actin, followed by incubation with horseradish peroxidase-conjugated secondary antibodies. Protein expression was determined by ECL. All reagents and antibodies were purchased from EMD Millipore, except XIAP, which was purchased from Abcam (Cambridge, UK).

Statistical analysis. Data are presented as means \pm standard deviation (SD). Student's t-test was used for analysis, and $\mathrm{P}<0.05$ was considered to indicate a statistically significant result.

\section{Results}

Curcumin induces apoptosis and suppresses $N F-\kappa B$-mediated tumor progression-related proteins in SAS/luc cells in a timedependent manner. Fig. 1A shows that curcumin killed more SAS/luc cells, as depicted by decreased cell viability, with increasing concentrations $(10-50 \mu \mathrm{M})$ and longer treatment time $(48 \mathrm{~h})$. The $\mathrm{IC}_{50}$ for curcumin was about $30 \mu \mathrm{M}$, which was selected for subsequent experiments. DNA laddering, which represents cell apoptosis, became more obvious in the SAS/luc cells when the cells were treated with curcumin for $48 \mathrm{~h}$ as compared to that at $24 \mathrm{~h}$ (Fig. 1B). Curcumin suppressed NF- $\mathrm{B} / \mathrm{DNA}$ binding activity also in a timedependent manner (Fig. 1C). Expression of apoptotic proteins (i.e. cleaved caspase- 3 , cleaved caspase- 8 and cytochrome $c$ ) increased while $\mathrm{NF}-\kappa \mathrm{B}-$ regulated effector proteins (i.e. angiogenesis protein VEGF, invasion protein MMP-9 and anti-apoptosis proteins BCL-2, XIAP and C-FLIP) decreased with curcumin treatment (Fig. 1D), both in a time-dependent manner.

Transfection of $p-I \kappa B \alpha M$ suppresses radiation-induced $N F-\kappa B$ activity and sensitizes SAS/luc cells to radiation. SAS cells were transfected with $\mathrm{p}-\mathrm{I} \kappa \mathrm{B} \alpha \mathrm{M}$, a super-repressor of $N F-\kappa B$, as a negative control of $N F-\kappa B$ activation. The radiation-induced $\mathrm{NF}-\kappa \mathrm{B} / \mathrm{DNA}$ binding activity was inhibited by $\mathrm{p}-\mathrm{I} \kappa \mathrm{B} \alpha \mathrm{M}$ (Fig. 2A). Transfection of $\mathrm{p}-\mathrm{I} \kappa \mathrm{B} \alpha \mathrm{M}$ significantly 
A

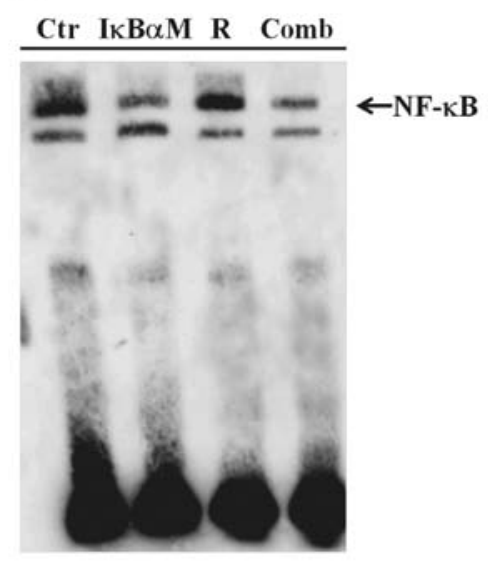

C

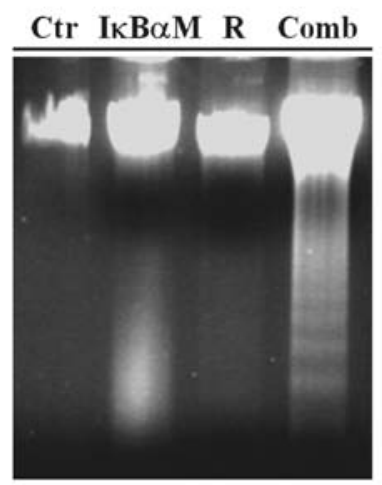

B

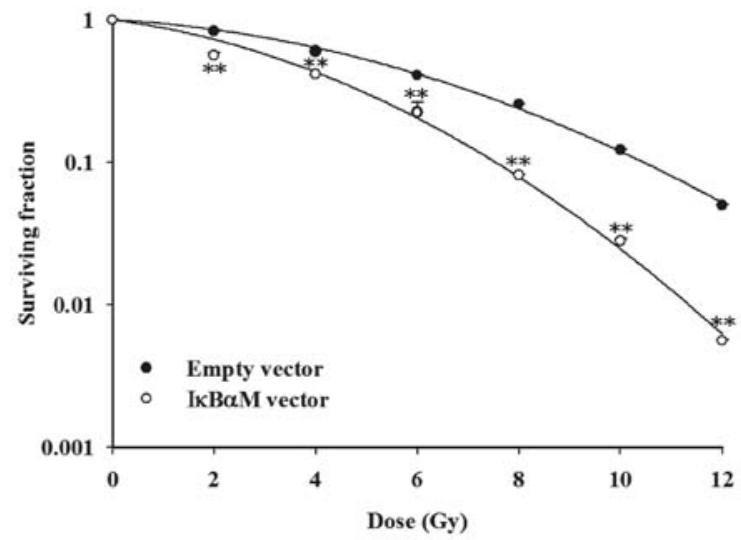

D

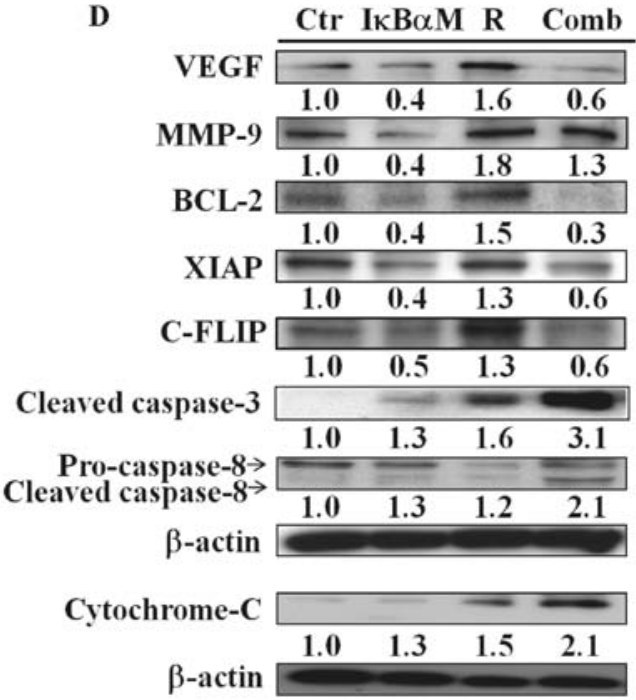

Figure 2. Transfection of $\mathrm{p}-\mathrm{I} \kappa \mathrm{B} \alpha \mathrm{M}$ sensitizes SAS cells to radiation. (A) Transfection of $\mathrm{p}-\mathrm{I} \kappa \mathrm{B} \alpha \mathrm{M}$ inhibited radiation-induced NF- $\kappa \mathrm{B}$ activity. The NF- $\kappa \mathrm{B} /$ DNA binding activity was evaluated with EMSA. (B) Transfection of p-I $\mathrm{B} \alpha \mathrm{M}$ significantly increased radiation-induced cytotoxicity. The surviving fraction was determined with a clonogenic survival assay. (C) Transfection of $\mathrm{p}-\mathrm{I} \kappa \mathrm{B} \alpha \mathrm{M}$ increased radiation-induced DNA fragmentation. (D) Transfection of $\mathrm{p}-\mathrm{I} \kappa \mathrm{B} \alpha \mathrm{M}$ decreased radiation-induced $\mathrm{NF}-\kappa \mathrm{B}$-regulated protein expression and increased radiation-induced apoptosis-related protein expression. Protein expression was assayed by western blotting. Representative data from three independent experiments are shown. ${ }^{* *} \mathrm{P}<0.01$ as compared with the empty vector. Ctr, empty vector; I $\mathrm{B} \alpha \mathrm{M}, \mathrm{I} \kappa \mathrm{B} \alpha \mathrm{M}$ vector; $\mathrm{R}$, radiation alone; Comb, combination.

increased radiation cytotoxicity at all doses (2-12 Gy) as compared with the transfection of the empty vector (Fig. 2B). Radiation-induced apoptosis, represented by DNA fragmentation (Fig. 2C) or increased apoptosis-related protein levels (Fig. 2D), was also enhanced following the transfection of $\mathrm{p}-\mathrm{I} \kappa \mathrm{B} \alpha \mathrm{M}$. Finally, the expression of radiation-induced $\mathrm{NF}-\kappa \mathrm{B}$ downstream effector proteins (i.e. VEGF, MMP-9, BCL-2, XIAP and C-FLIP) was inhibited by the transfection of p-IкB $\alpha \mathrm{M}$ (Fig. 2D).

Curcumin suppresses radiation-induced $N F-\kappa B$ activity and synergistically sensitizes $S A S / l u c$ cells to radiation. Curcumin inhibited radiation-induced $\mathrm{NF}-\kappa \mathrm{B} / \mathrm{DNA}$ binding activity (Fig. 3A). The combination of curcumin with radiation significantly decreased the survival fraction at all doses (2-12 Gy) when compared with the radiation alone group (Fig. 3B). Synergistic effects were noticed with radiation doses $>2$ Gy (Table I). In addition, curcumin increased radiation-induced
Table I. Effect of $30 \mu \mathrm{M}$ curcumin combined with various doses of radiation on SAS/luc cells.

\begin{tabular}{llll}
\hline Radiation (Gy) & $\mathrm{SF}_{\mathrm{R}}$ & \multicolumn{1}{c}{$\mathrm{SF}_{\mathrm{R}+\mathrm{C}}$} & $\mathrm{SF}_{\mathrm{R}} \times \mathrm{SF}_{\mathrm{C}}$ \\
\hline 2 & 0.56 & 0.37 (sub-additivity) & 0.28 \\
4 & 0.42 & 0.13 (synergism) & 0.21 \\
6 & 0.22 & 0.05 (synergism) & 0.11 \\
8 & 0.08 & 0.01 (synergism) & 0.04 \\
10 & 0.03 & 0.003 (synergism) & 0.01 \\
12 & 0.01 & 0.0005 (synergism) & 0.00 \\
\hline
\end{tabular}

apoptosis as shown by DNA fragmentation (Fig. 3C) and increased apoptotic proteins levels (i.e. cleaved caspase-3, cleaved caspase-8 and cytochrome $c$ in Fig. 3D). Fig. 3D indicates that curcumin suppressed radiation-induced $\mathrm{NF}-\kappa \mathrm{B}$ 

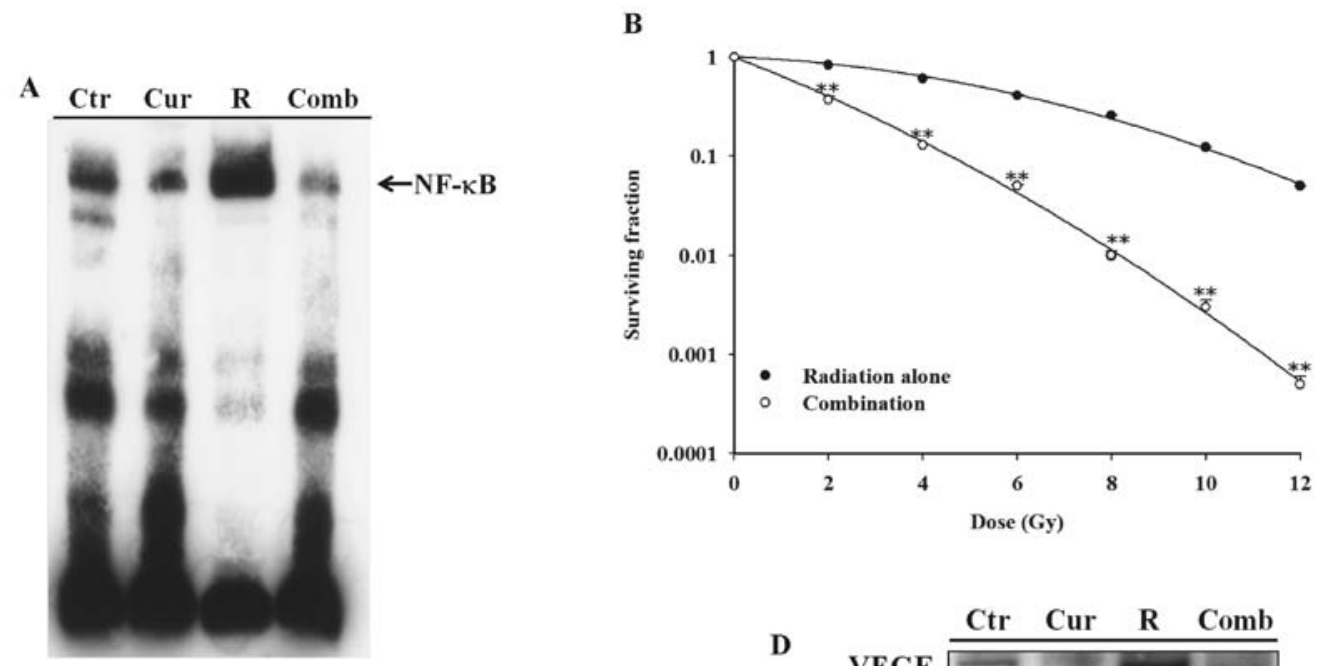

C
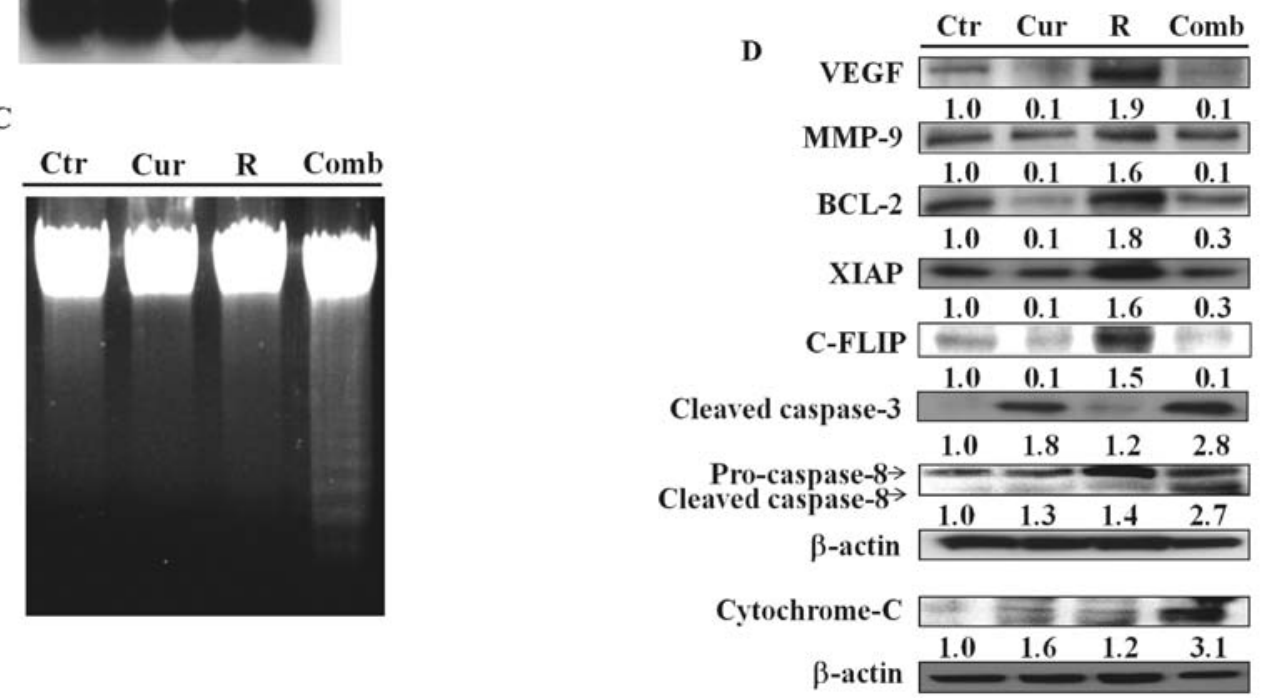

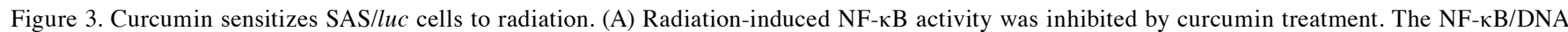
binding activity was evaluated with EMSA. (B) Curcumin significantly increased radiation-induced cytotoxicity. SAS/luc cells were treated with or without $30 \mu \mathrm{M}$ curcumin followed by immediate irradiation with various doses (see context for detail). The surviving fraction was determined with clonogenic survival assay. (C) Curcumin increased radiation-induced DNA fragmentation. (D) Curcumin decreased radiation-induced NF-kB-regulated protein expression and increased radiation-induced apoptosis-related protein expression. Protein expression was assayed by western blotting. (Representative data from three independent experiments are shown. ${ }^{* *} \mathrm{P}<0.01$ as compared with radiation alone. Ctr, control; Cur, curcumin alone; R, radiation alone; Comb, combination.

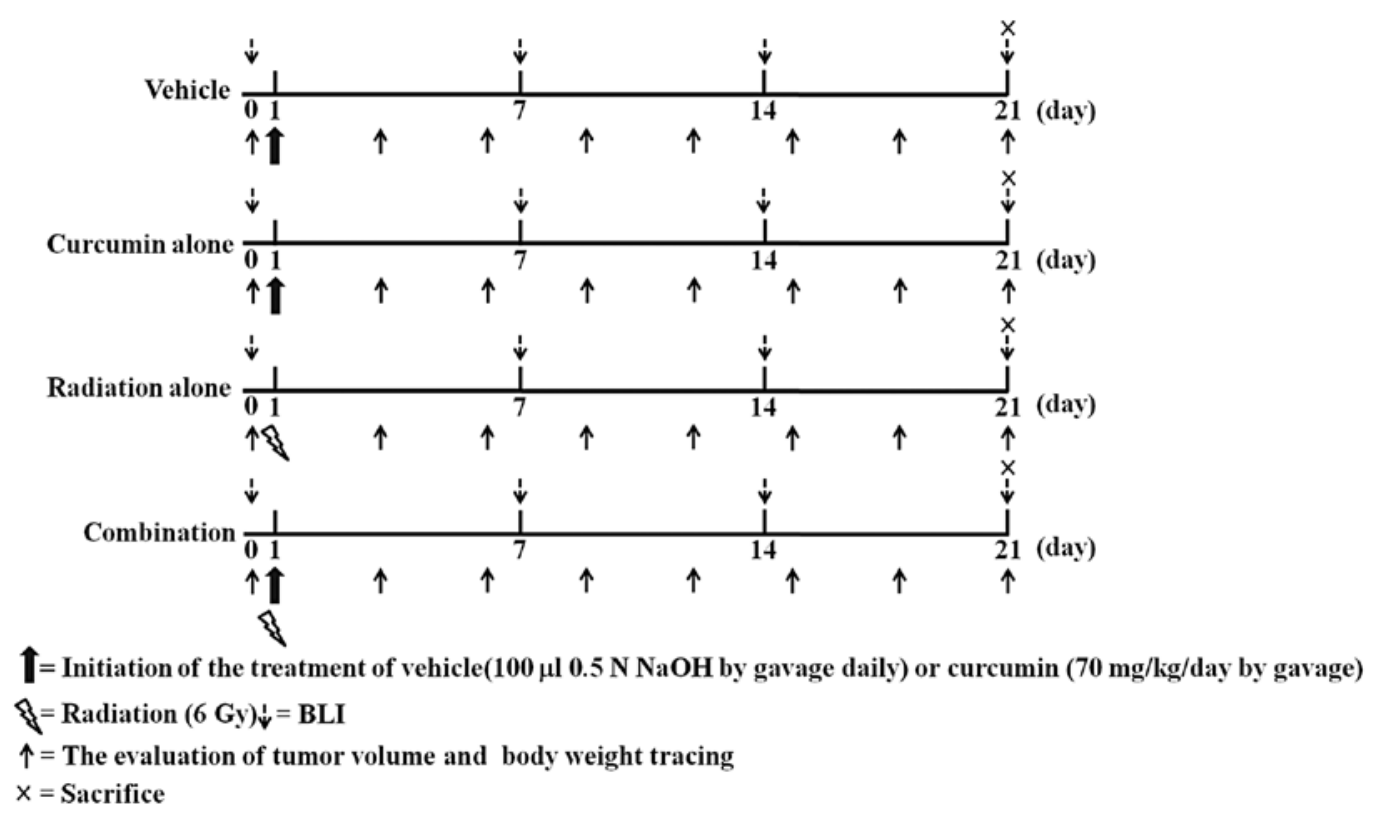

Figure 4. Schematic depiction of the experimental design. SAS/luc tumor-bearing mice were divided into four groups: vehicle-treated control group; radiationtreated (single $6 \mathrm{~Gy}$ on day 1) group; curcumin-treated ( $70 \mathrm{mg} / \mathrm{kg} /$ day by gavage from day 1$)$ group; and combined treatment (curcumin plus radiation) group. 

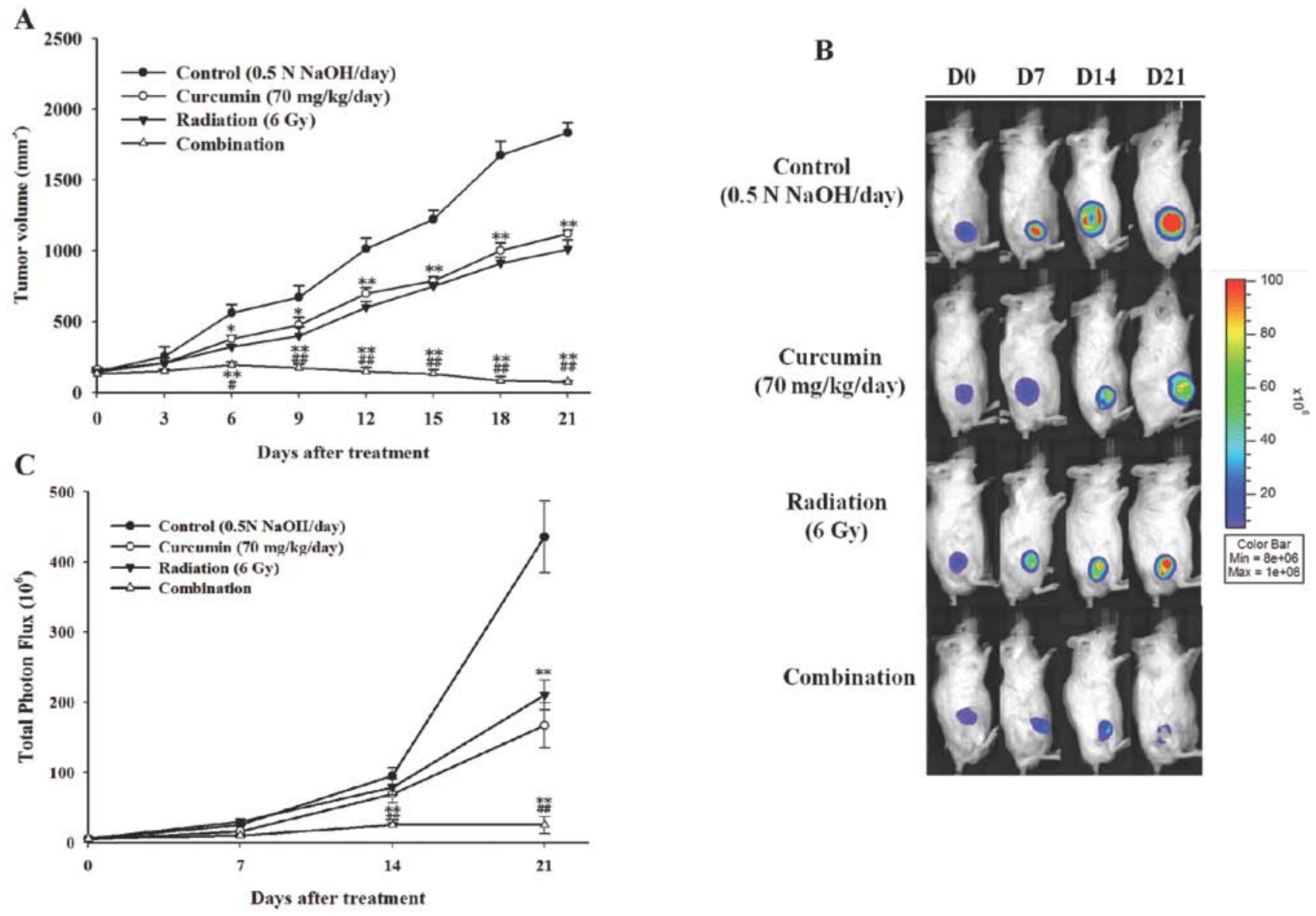

$\mathbf{E}$
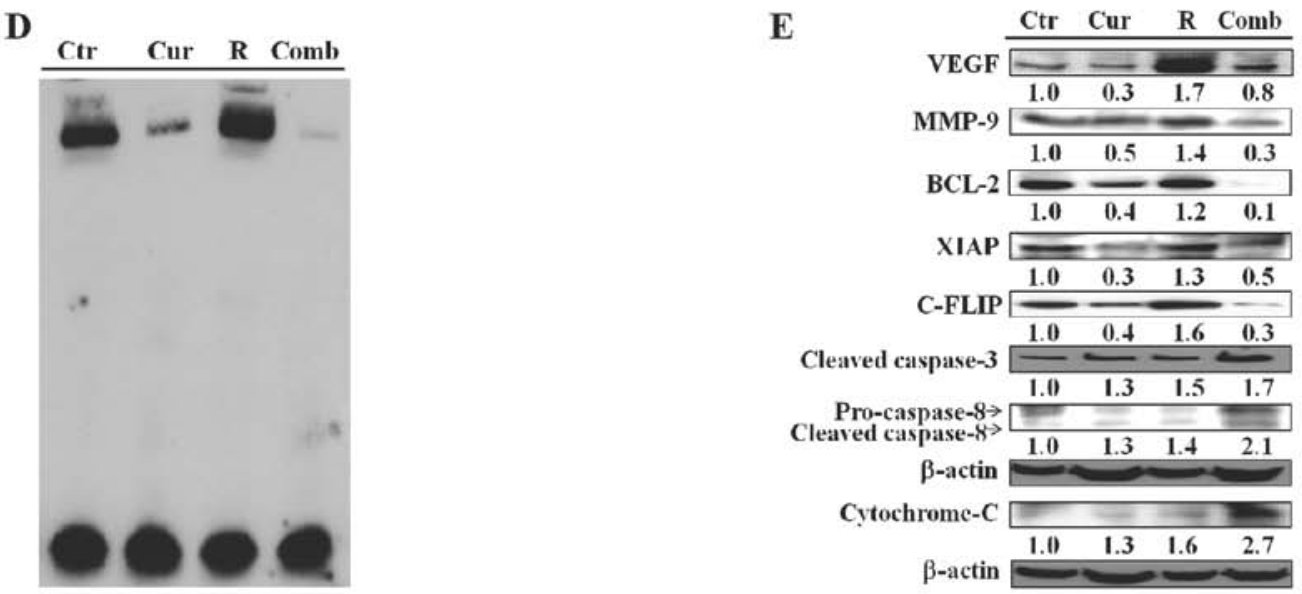

Figure 5. Curcumin sensitizes SAS/luc tumor-bearing mice to radiation. (A) The combined treatment group (combination) exhibited significantly inhibited tumor growth when compared with the other groups. (B) The therapeutic efficacy in SAS/luc tumor-bearing mice was evaluated with bioluminescent imaging (BLI). (C) The photon flux of BLI was quantified, and the value was the lowest in the combination group when compared with the other groups. (D) Curcumin

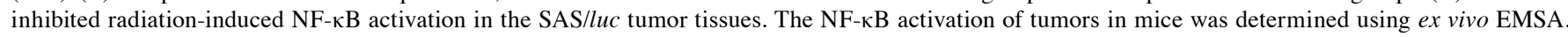
(E) Ex vivo western blotting demonstrated that curcumin decreased radiation-induced NF-kB-regulated effector protein expression and increased radiationinduced apoptotic protein expression in the SAS/luc tumor tissues ( $\mathrm{n}=5$ in each group). Representative data from three independent experiments are shown. ${ }^{*} \mathrm{P}<0.05,{ }^{* * *} \mathrm{P}<0.01$ as compared with the control. ${ }^{\#} \mathrm{P}<0.05,{ }^{\# \#} \mathrm{P}<0.01$ as compared with the other treatment groups.

downstream effector protein expression (i.e. VEGF, MMP-9, BCL-2, XIAP and C-FLIP). These findings were identical to those observed in the aforementioned $\mathrm{p}-\mathrm{I} \kappa \mathrm{B} \alpha \mathrm{M}$-transfected group.

Curcumin enhances the therapeutic efficacy of radiation in the SAS/luc tumor-bearing mice. Fig. 4 depicts a flow chart of the in vivo experiment. SAS/luc tumor-bearing mice were divided into four groups: the vehicle-treated control (vehicle) group, the curcumin-treated (curcumin alone) group, the radiation-treated (radiation alone) group, and the combined treatment (combination) group. Mice were treated according to the grouping when the tumor volume reached $70 \mathrm{~mm}^{3}$. Fig. 5A depicts the tumor growth curve measured by caliper during the experiment. All the treatment groups showed significantly enhanced inhibition of tumor growth when compared with the 


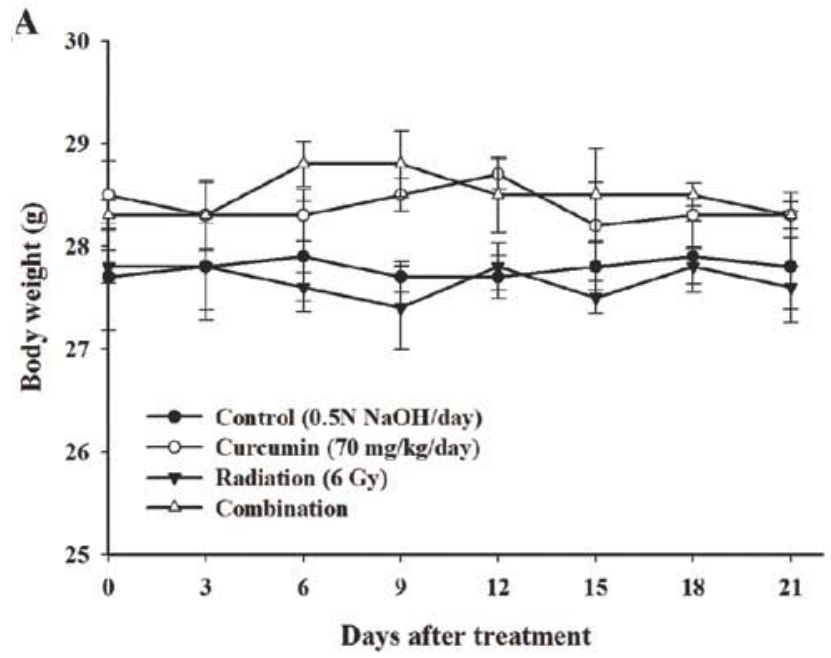

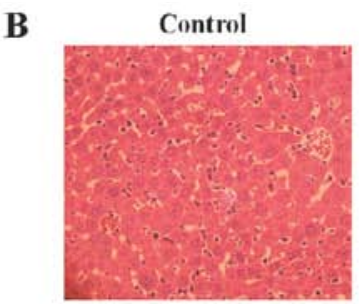

Radiation alone

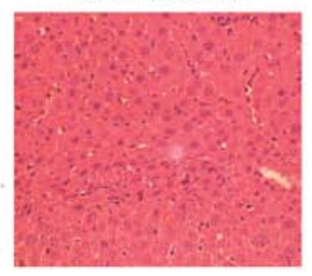

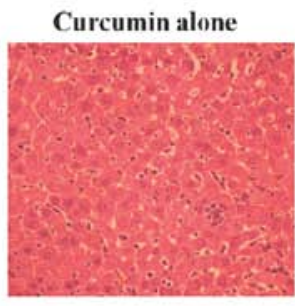

Combination

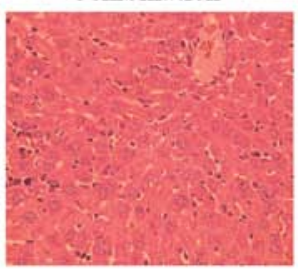

Figure 6. Low toxicity of curcumin treatment. (A) No significant body weight changes were noted in all groups. This result indicates that curcumin plus radiation was well tolerated by the mice. (B) Pathological examination with H\&E staining showed no liver parenchymal change in all groups.

control group. The combined treatment group (combination) exhibited optimal tumor control and a significantly smaller tumor volume on day 21 in comparison with the curcumintreated (curcumin alone) or radiation-treated (radiation alone) group. BLI was also used to evaluate the therapeutic efficacy. On day 21 as shown in Fig. 5B and C, photons emitted from the tumors of the treatment groups were significantly lower than photons from the tumors of the control group. Photon flux of the combination group was significantly lower when compared with the photon flux in the curcumin or radiation alone group. As predicted in the in vitro data, ex vivo EMSA and western blotting showed that curcumin inhibited radiation-induced $\mathrm{NF}-\kappa \mathrm{B} / \mathrm{DNA}$ binding activity, increased radiation-induced apoptotic protein levels, and suppressed radiation-induced $\mathrm{NF}-\kappa \mathrm{B}$ downstream effector protein expression (Fig. 5D and $\mathrm{E}$ ). We traced body weight changes of the mice to evaluate the potential toxicity caused by the treatments. There were no significant changes (i.e. within $20 \%$ of the original weight) observed in all four groups (Fig. 6A). Pathological examination showed no difference in the mouse liver morphology among all the groups (Fig. 6B).

\section{Discussion}

Radiotherapy- or chemotherapy-induced NF- $\kappa \mathrm{B}$ activity has been reported in numerous studies and is closely correlated with radioresistance or chemoresistance (5). Inappropriate $\mathrm{NF}-\kappa \mathrm{B}$ activation results in malignant behavior and antiapoptotic activity of OSCC $(24,25)$. In clinical practice, it was found that overexpression of $\mathrm{NF}-\kappa \mathrm{B}$ is highly correlated with poor treatment outcome (26). We previously showed that curcumin inhibits the proliferation of human OSCC both in vitro and in vivo by inducing apoptosis (18). However, inhibition of $\mathrm{NF}-\kappa \mathrm{B}$ activation does not always result in enhanced radiosensitivity. Instead, radiosensitization is a cell type-specific phenomenon following NF- $\kappa \mathrm{B}$ suppression (27). The transfection of $\mathrm{p}-\mathrm{I} \kappa \mathrm{B} \alpha \mathrm{M}$, a super repressor of NF- $\mathrm{NB}$, inhibits 12-O-tetradecanoylphorbol-13-acetate (TPA)-induced $N F-\kappa B$ activity (19) and increases radiation- induced cytotoxicity in breast cancer (28). We found that the radiation-induced $\mathrm{NF}-\kappa \mathrm{B} / \mathrm{DNA}$ binding activity and $\mathrm{NF}-\kappa \mathrm{B}-$ regulated effector protein expression were inhibited by

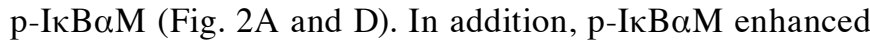
radiation-induced cytotoxicity and apoptosis via the mitochondrial-dependent and -independent pathways as shown in Fig. 2B-D. These results together suggest that inhibition of radiation-induced $N F-\kappa B$ activity is able to sensitize SAS cells to radiation (Fig. 2).

Several methods have been suggested to suppress $N F-\kappa B$ activation and various synthetic drugs or natural compounds are used to inhibit radiation-induced NF- $\mathrm{B}$ activity $(29,30)$. Natural compounds are preferred in clinical practice due to low cytotoxicity and multiple mechanisms of action $(14,31)$. Curcumin is a natural compound capable of decreasing cell survival, invasion, and angiogenesis via NF- $\mathrm{B}$ signal cascade suppression in several types of cancers $(31,32)$. Our experimental results on the OSCC cell line SAS/luc showed that curcumin inhibited cell proliferation (Fig. 1A), constitutive $\mathrm{NF}-\kappa \mathrm{B} / \mathrm{DNA}$ binding activity (Fig. 1C) and NF- $\kappa \mathrm{B}$ downstream effector protein expression (Fig. 1D) while it induced apoptosis via the mitochondrial-dependent and -independent pathways (Fig. 1B and D). Furthermore, curcumin inhibited radiation-induced $\mathrm{NF}-\kappa \mathrm{B} / \mathrm{DNA}$ binding activity (Fig. 3A) and $\mathrm{NF}-\kappa \mathrm{B}$-regulated effector protein expression (Fig. 3D) in addition to enhancing radiation cytotoxicity (Fig. 3B) and apoptosis (Fig. 3C and D). When compared with the surviving fraction of the radiation alone group, the combination group showed the synergistic effect (Table I) of curcumin. All these findings indicate that curcumin sensitizes SAS cells to radiation in vitro, similar to that observed in $\mathrm{p}-\mathrm{I} \kappa \mathrm{B} \alpha \mathrm{M}$-transfected cells, via inhibition of radiation-induced NF- $\kappa \mathrm{B}$ activity.

Fig. 5A-C shows that curcumin enhanced the antitumor effect of radiation in SAS/luc cells in vivo through suppression of radiation-induced NF- $\kappa \mathrm{B} / \mathrm{DNA}$ binding activity (Fig. 5D) and NF- $\mathrm{BB}$-regulated effector protein expression (Fig. 5E). The body weight changes of all the mice throughout the entire experiment were within $20 \%$ of the original weight (Fig. 6A). In addition, no evidence of liver parenchymal injury 
or morphologic change was found by pathological examination. Both results indicated that there was no marked toxicity of curcumin treatment. No toxicity has been reported for curcumin at a single dose of $12 \mathrm{~g}$ /day by oral administration in a clinical trial (33). Thus, curcumin may be an ideal radiosensitizer for future clinical use because of its radiosensitizing effect and extremely low toxicity.

In conclusion, the present study demonstrated that curcumin sensitizes human OSCC to radiation via inhibition of radiation-induced NF- $\mathrm{NB}$ activity. Combination of curcumin with radiation exerts a synergistic effect in vitro and enhances tumor control in vivo without noticeable toxicity.

\section{Acknowledgements}

The present study was supported by grants NSC 97-2314-B-010-045-MY3 and NSC 97-2314-B-010-046-MY3 from the National Science Council, Taipei, Taiwan. The imaging facility was supported by the Taiwan Mouse Clinic.

\section{References}

1. Myers JN, Greenberg JS, Mo V and Roberts D: Extracapsular spread. A significant predictor of treatment failure in patients with squamous cell carcinoma of the tongue. Cancer 92: 3030-3036, 2001.

2. Kunnumakkara AB, Diagaradjane $\mathrm{P}$, Guha $\mathrm{S}$, et al: Curcumin sensitizes human colorectal cancer xenografts in nude mice to gamma-radiation by targeting nuclear factor- $\mathrm{\kappa B}$-regulated gene products. Clin Cancer Res 14: 2128-2136, 2008.

3. Kunigal S, Lakka SS, Joseph P, Estes N and Rao JS: Matrix metalloproteinase-9 inhibition down-regulates radiation-induced nuclear factor- $\mathrm{\kappa B}$ activity leading to apoptosis in breast tumors. Clin Cancer Res 14: 3617-3626, 2008.

4. Veeraraghavan J, Natarajan M, Aravindan S, Herman TS and Aravindan N: Radiation-triggered tumor necrosis factor (TNF) $\alpha-\mathrm{NF} \kappa \mathrm{B}$ cross-signaling favors survival advantage in human neuroblastoma cells. J Biol Chem 286: 21588-21600, 2011.

5. Li $\mathrm{F}$ and Sethi G: Targeting transcription factor NF- $\kappa \mathrm{B}$ to overcome chemoresistance and radioresistance in cancer therapy. Biochim Biophys Acta 1805: 167-180, 2010.

6. Allen CT, Ricker JL, Chen Z and Van Waes C: Role of activated nuclear factor- $\kappa \mathrm{B}$ in the pathogenesis and therapy of squamous cell carcinoma of the head and neck. Head Neck 29: 959-971, 2007.

7. Bancroft CC, Chen Z, Dong G, et al: Coexpression of proangiogenic factors IL-8 and VEGF by human head and neck squamous cell carcinoma involves coactivation by MEK-MAPK and IKK-NF- $\kappa$ B signal pathways. Clin Cancer Res 7: 435-442, 2001.

8. Henriques AC, de Matos FR, Galvao HC and Freitas Rde A: Immunohistochemical expression of MMP-9 and VEGF in squamous cell carcinoma of the tongue. J Oral Sci 54: 105-111, 2012.

9. Rahmani A, Alzohairy M, Babiker AY, Rizvi MA and Elkarimahmad HG: Clinicopathological significance of PTEN and bcl 2 expressions in oral squamous cell carcinoma. Int J Clin Exp Pathol 5: 965-971, 2012.

10. Nagi C, Xiao GQ, Li G, Genden E and Burstein DE: Immunohistochemical detection of X-linked inhibitor of apoptosis in head and neck squamous cell carcinoma. Ann Diagn Pathol 11: 402-406, 2007.

11. Bentires-Alj M, Barbu V, Fillet M, et al: NF- $\kappa \mathrm{B}$ transcription factor induces drug resistance through MDR1 expression in cancer cells. Oncogene 22: 90-97, 2003.

12. Kuo YC, Lin WC, Chiang IT, et al: Sorafenib sensitizes human colorectal carcinoma to radiation via suppression of NF- $\kappa \mathrm{B}$ expression in vitro and in vivo. Biomed Pharmacother 66: 12-20, 2012.
13. Cooper JS, Pajak TF, Forastiere AA, et al: Postoperative concurrent radiotherapy and chemotherapy for high-risk squamous-cell carcinoma of the head and neck. N Engl J Med 350: 1937-1944, 2004

14. Goel A, Kunnumakkara AB and Aggarwal BB: Curcumin as 'Curecumin': from kitchen to clinic. Biochem Pharmacol 75: 787-809, 2008

15. Shi HS, Gao X, Li D, et al: A systemic administration of liposomal curcumin inhibits radiation pneumonitis and sensitizes lung carcinoma to radiation. Int J Nanomed 7: 2601-2611, 2012.

16. LoTempio MM, Veena MS, Steele HL, et al: Curcumin suppresses growth of head and neck squamous cell carcinoma. Clin Cancer Res 11: 6994-7002, 2005

17. Khafif A, Lev-Ari S, Vexler A, et al: Curcumin: a potential radio-enhancer in head and neck cancer. Laryngoscope 119: 2019-2026, 2009

18. Lin YC, Chen HW, Kuo YC, Chang YF, Lee YJ and Hwang JJ: Therapeutic efficacy evaluation of curcumin on human oral squamous cell carcinoma xenograft using multimodalities of molecular imaging. Am J Chin Med 38: 343-358, 2010.

19. Chiang IT, Liu YC, Wang WH, et al: Sorafenib inhibits TPA-induced MMP-9 and VEGF expression via suppression of ERK/NF- $\kappa \mathrm{B}$ pathway in hepatocellular carcinoma cells. In Vivo 26: 671-681, 2012.

20. Valeriote F and Lin H: Synergistic interaction of anticancer agents: a cellular perspective. Cancer Chemother Rep 59: 895-900, 1975.

21. Carpentier Y, Demange L, Loirette M, Hivet J and Desoize B: Chronology of combined chemotherapy (5FU) and radiotherapy. I. In vitro study. Anticancer Res 13: 2177-2180, 1993.

22. Wang WH, Chiang IT, Ding K, et al: Curcumin-induced apoptosis in human hepatocellular carcinoma $\mathrm{J} 5$ cells: critical role of $\mathrm{Ca}^{2+}$ dependent pathway. Evid Based Complement Alternat Med 2012: 512907, 2012

23. Burgos JS, Rosol M, Moats RA, et al: Time course of bioluminescent signal in orthotopic and heterotopic brain tumors in nude mice. Biotechniques 34: 1184-1188, 2003.

24. Nakayama H, Ikebe T, Beppu M and Shirasuna K: High expression levels of nuclear factor kappaB, IkappaB kinase alpha and Akt kinase in squamous cell carcinoma of the oral cavity. Cancer 92: 3037-3044, 2001.

25. Bindhu OS, Ramadas K, Sebastian P and Pillai MR: High expression levels of nuclear factor kappa $B$ and gelatinases in the tumorigenesis of oral squamous cell carcinoma. Head Neck 28: 916-925, 2006.

26. Yoshida K, Sasaki R, Nishimura H, et al: Nuclear factor- $\kappa \mathrm{B}$ expression as a novel marker of radioresistance in early-stage laryngeal cancer. Head Neck 32: 646-655, 2010.

27. Ahmed KM and Li JJ: NF-kB-mediated adaptive resistance to ionizing radiation. Free Radic Biol Med 44: 1-13, 2008.

28. Wang T, Hu YC, Dong S, et al: Co-activation of ERK, NF- $\kappa B$, and $\mathrm{GADD}_{45} \beta$ in response to ionizing radiation. $\mathrm{J}$ Biol Chem 280: 12593-12601, 2005.

29. Xu Y, Fang F, St Clair DK, Sompol P, Josson S and St Clair WH: SN52, a novel nuclear factor- $\kappa \mathrm{B}$ inhibitor, blocks nuclear import of RelB:p52 dimer and sensitizes prostate cancer cells to ionizing radiation. Mol Cancer Ther 7: 2367-2376, 2008.

30. Dong GZ, Oh ET, Lee H, Park MT, Song CW and Park HJ: $\beta$-lapachone suppresses radiation-induced activation of nuclear factor- $\kappa$ B. Exp Mol Med 42: 327-334, 2010.

31. Kunnumakkara AB, Anand P and Aggarwal BB: Curcumin inhibits proliferation, invasion, angiogenesis and metastasis of different cancers through interaction with multiple cell signaling proteins. Cancer Lett 269: 199-225, 2008.

32. Chendil D, Ranga RS, Meigooni D, Sathishkumar S and Ahmed MM: Curcumin confers radiosensitizing effect in prostate cancer cell line PC-3. Oncogene 23: 1599-1607, 2004.

33. Lao CD, Ruffin MT IV, Normolle D, et al: Dose escalation of a curcuminoid formulation. BMC Complement Altern Med 6: 10, 2006. 